\title{
Alternate Design Concept for the SSC Dipole Magnet Cryogenic Support Post
}

\author{
A. Lipski, T. H. Nicol and R. Richardson \\ Fermi National Accelerator Laboratory \\ P.O. Box 500, Batavia, Illinois 60510
}

March 1991

* Presented at the Third Annual International Industrial Symposium on the Super Collider [IISSC], Atlanta, Georgia, March 13-15, 1991. 


\title{
ALTERNATE DESIGN CONCEPT FOR THE SSC DIPOLE MAGNET CRYOGENIC SUPPORT POST
}

\author{
A. Lipski, T.H. Nicol and R. Richardson \\ Fermilab National Accelerator Laboratory* \\ Box 500 \\ Batavia, IL 60510
}

\begin{abstract}
New materials and developments in the field of advanced composites have created the opportunity to take a fresh look into the design of the cryogenic supports for SSC collider dipole cryostats. Although the present reentrant post design meets the structural and thermal requirements, its assembly requires precision and proficiency. The objective of the proposed alternate concept is to reduce the overall cost of the support post by means of simplifying and optimizing its component design and assembly process. The present shrink fitted tube assembly may potentially be replaced by injection molded parts. New resin systems with lower thermal conductivity and high strength properties enable the utilization of automated production techniques such as injection molding and filament winding. This paper will provide analysis and design information for the alternate support post concept and compare its test performance and cost to the present support post.
\end{abstract}

\section{INTRODUCTION}

The support post is part of the suspension system in the superconducting magnet. Its main two functions are:

a. To support the cold mass and thus to withstand the various loads resulting during operation, storage and transport of the magnet.

b. To serve as an insulating medium for heat conducted from the environment into the cold mass.

The cold mass assembly is supported vertically and laterally at five locations along its length. To distribute the axial load between all the supports, tie bars connect the top of each post. Thus, any axial load acting on the cold mass is transmitted to the center post and distributed to the other posts via the tie bars. 1

Table 1 provides a summary of the structural and thermal design criteria for the support post.

* Operated by Universities Research Association, Inc., under contract with the U.S. Department of Energy. 
Table 1. SSC Dipole Structural and Thermal Load Summary2

$\begin{array}{lll}\text { Shipping and Handling Loads: } & \begin{array}{l}\text { Vertical } \\ \text { Lateral } \\ \text { Axial }\end{array} & \begin{array}{l}2.0 \mathrm{G} \\ 1.0 \mathrm{G} \\ 1.5 \mathrm{G}\end{array} \\ & & \\ \text { Budgeted Conduction Heat Loads } & 80 \mathrm{~K} & 3.16 \mathrm{~W} \\ \text { per Magnet: } & 20 \mathrm{~K} & 0.48 \mathrm{~W} \\ & 4.5 \mathrm{~K} & 0.032 \mathrm{~W}\end{array}$

Any alternate design to the present reentrant post will have to meet or come close to the post design criteria and requirements.

The reentrant post consists of inner and outer composite tubes connected by an intermediate stainless steel transition tube. The composite tubes are captured in both ends with stainless steel end plates via shrink fit joints. Figure 1 illustrates a cross section through one of the support posta

The reentrant post assembly is complex and expensive. It requires precise control of the tube wall thicknesses as well as close tolerances of the stainless steel end plates in order to achieve an effective shrink fitted connection.

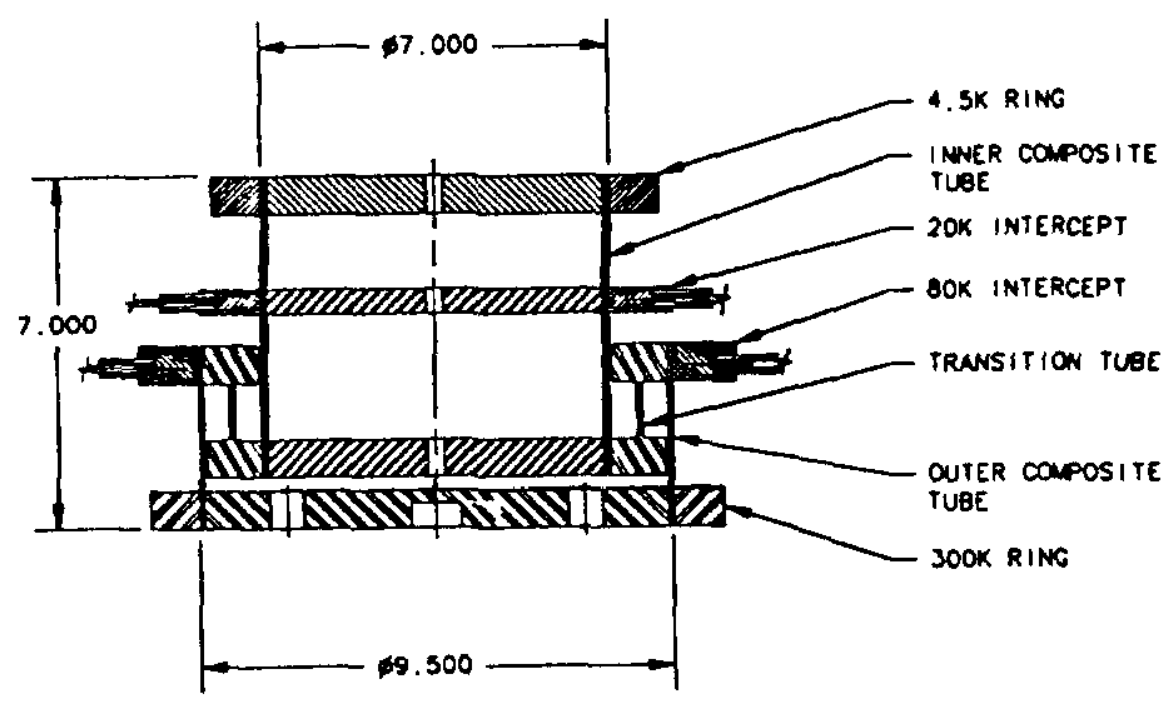

Fgure 1. SSC Reentrant Support Post Cross Section 
The firt serious attempt to introduce a simplified cost reduced alternative to the reentrant post was presented during the RHIC Magnet Design Review on February, 1990 at Brookhaven National Laboratory. ${ }^{3}$ The preliminary results of the feasibility study for an injection molded composite support post were very encouraging.

The conceptual injection molded composite (IMC) support post assembly for the SSC Dipole Magnet consists of three columnated IMC flanged cylinders separated by two spacers. The sections and the spacers are captured by bolts using backing rings under the bolt heads and the nuts for better load distribution on the flange as illustrated in Figure 2.

The intent of this paper is to illustrate a design concept of an IMC support post for the SSC Dipole Magnet. This preliminary concept does not suggest the final design configuration. It merely offers a tool to examine the correlation between analysis and testing as well as selection of the proper material.

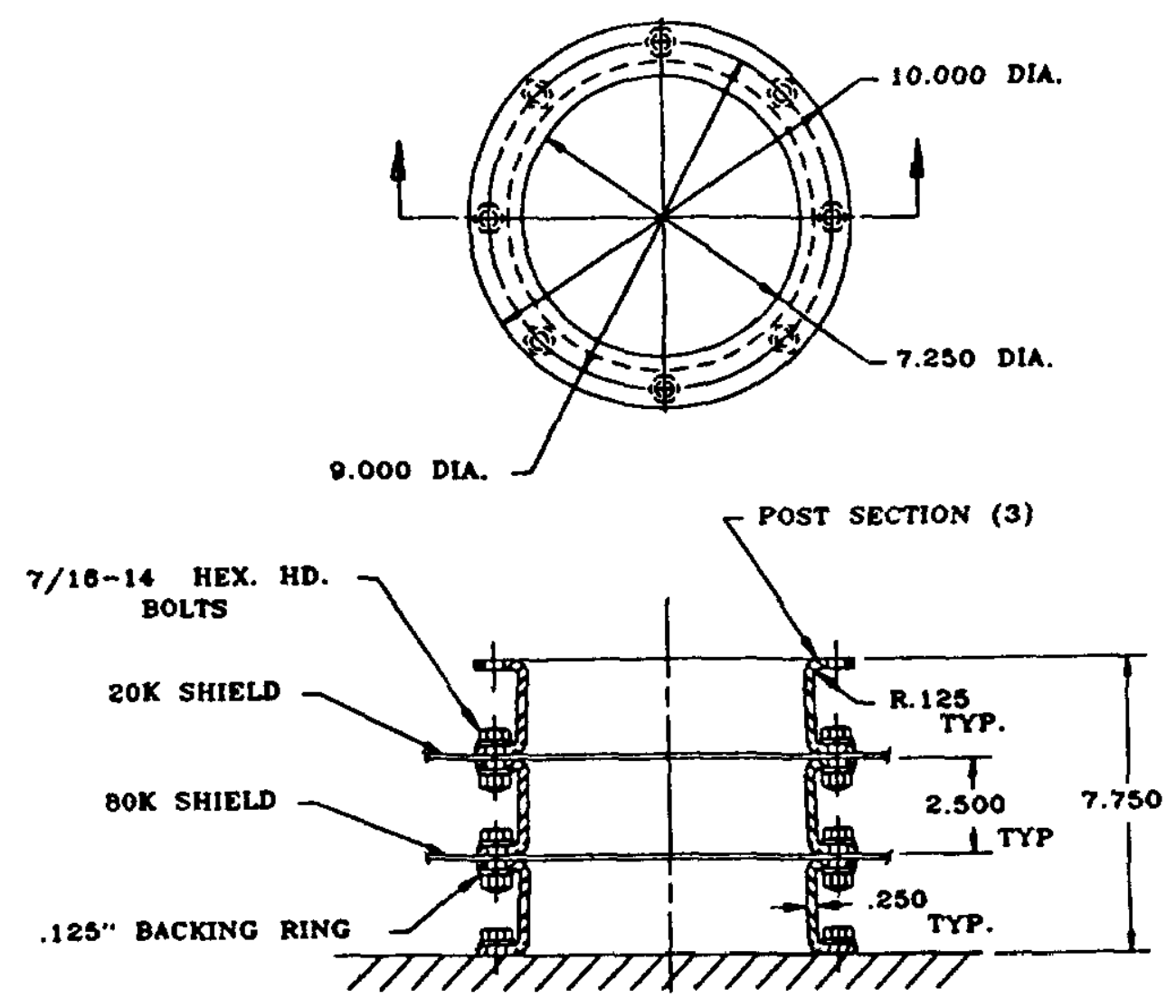

Fgure 2. SSC IMC Conceptual Support Post Cross Section 


\section{MATERIAL SELECTION}

As referenced previously, the two primary functions of the support post are to resiat structural loads and insulate the cold mass from the environment. Thus, those were the two primary requirements which governed the search for the ideal IMC candidate material. We are looking to maximize the relationship between these two material properties which can be described as:

$$
\frac{\text { F.M. }}{\text { T.C. }} \rightarrow \text { Max. }
$$

where:

$$
\begin{aligned}
& \text { F.M. - Fexural modulus } \\
& \text { T.C. - Thermal conductivity }
\end{aligned}
$$

Namely, we are looking for a material with the highest ratio possible between strength and thermal resistance.

In addition to these primary requirements, the IMC resin must withstand exposure to the radiation levels of the accelerator, thereby ensuring the continuous performance of the support post over its 25 year life span.

Two long term effects which must be taken into consideration when selecting material for the IMC are creep and aging. Creep results in a dimensional change due to a continuous loading condition, while aging is the effect of the environment on the material properties.

While the flexural strength, thermal conductivity and creep are all temperature dependent, radiation and aging are not necessarily so. In fact, low temperature is a beneficial factor in this case since fexural strength increases while thermal conductivity and creep are reduced at low temperatures.

The operating environment for the IMC will have the following conditions: ${ }^{2}$

- Temperature - as low as $-450^{\circ} \mathrm{F}$

- Radiation - as high as $3 \times 10^{5} \mathrm{RAD}$ and $3.2 \times 10^{13} \frac{\text { Neutron }}{\mathrm{cm}^{2}}$ over 25 years

- Vacuum $-10-7$ Torr at operating conditions

The following materials were found to be potentially qualified for usewith the IMC support post prototype testing.

- G.E. Ultem 2300 polyetherimide resin (30\% glass reinforced)

- ICI Victrex 450GL30 polyetheretherkeotone (PEEK) (30\% glass reinforced)

- Amoco Xydar G430 liquid crystal polymer (LCP) (30\% glass reinforced)

- Amoco Torlon 5030 poly (Amide-imide) (30\% glass reinforced)

- Dupont Vespel sp-1 polyimide resin (unfilled base resin)

Table 2 summarizes the mechanical and physical characteristics of these materials. 
Table 2. Mechanical and physical characteristics* (taken from vendor data)

\begin{tabular}{|c|c|c|c|c|c|c|c|c|c|c|}
\hline $\begin{array}{l}\text { Trade } \\
\text { name }\end{array}$ & $\begin{array}{l}\text { Tensilo } \\
p s i\end{array}$ & $\begin{array}{l}\text { Compress. } \\
\text { psl }\end{array}$ & $\begin{array}{l}\text { Shear } \\
\text { pel }\end{array}$ & $\begin{array}{l}\text { T.C. } \\
\text { MW/mK }\end{array}$ & $\begin{array}{l}\text { CTE } \\
\text { in/ln } / \cdot F\end{array}$ & $\begin{array}{l}\text { Flex mod. } \\
\text { osi } \times 10^{5}\end{array}$ & Creep & Rad. & $\begin{array}{l}\text { Mold } \\
\text { abillity }\end{array}$ & Material \\
\hline $\begin{array}{l}\text { Uitem } \\
2300\end{array}$ & 24500 & 30700 & 14000 & 230 & $1.1 \times 10^{-5}$ & 13 & Better & $\begin{array}{l}10^{9} \\
810\end{array}$ & Better & $\begin{array}{l}\text { P.E.I-30\% } \\
\text { fiber glass }\end{array}$ \\
\hline $\begin{array}{l}\text { Victrex } \\
450 \text { G130 }\end{array}$ & 22800 & 25000 & 14100 & 430 & $1.2 \times 10^{-5}$ & 15 & $\begin{array}{l}\text { Vory } \\
\text { good }\end{array}$ & $\begin{array}{l}10^{6} \\
\text { PND } \\
\end{array}$ & Good & $\begin{array}{l}\text { PEEK } 30 \% \\
\text { fiber glass }\end{array}$ \\
\hline $\begin{array}{l}\text { Xydar } \\
\text { G430 }\end{array}$ & 19800 & 9800 & & 220 & $.45 \times 10^{-5}$ & 20.5 & Bed & Good & Fair & $\begin{array}{l}\text { L.C.P. - } 30 \% \\
\text { fiber glass }\end{array}$ \\
\hline $\begin{array}{l}\text { Torlon } \\
5030\end{array}$ & 29000 & 38000 & 20000 & 360 & $.9 \times 10.5$ & 17 & Best & $\begin{array}{r}10^{9} \\
1 \times 0\end{array}$ & Hard & $\begin{array}{l}\text { PA.1. } 30 \% \\
\text { fiber glass }\end{array}$ \\
\hline $\begin{array}{l}\text { Vespol } \\
\text { Sp-1 }\end{array}$ & 10500 & & & 350 & $3 \times 10^{-5}$ & 3.6 & Excellent & $\begin{array}{l}10^{\circ} \\
\text { PND }\end{array}$ & Formed & $\begin{array}{l}\text { Polymide } \\
\text { unfilled }\end{array}$ \\
\hline $\begin{array}{l}\text { Spaulding } \\
\text { G11.Cr }\end{array}$ & 50000 & 70000 & & 700 & $2 \times 10.5$ & 40 & Botter & $\begin{array}{l}10^{\circ} \\
\text { RAD }\end{array}$ & Nons & $\begin{array}{l}\text { Epoxy - } \\
\text { fiber glass }\end{array}$ \\
\hline
\end{tabular}

* Measured at room temperature

THE MODEL

The main purpose of this project was to study the feasibility of replacing the existing reentrant post with an injection molded composite (IMC) support post. Principal objectives of the study were:

1. To identify the most suitable material

2. To establish an analytical tool supported by lab testing.

It was decided early in the program to adopt a simplified version for the structure.

As illustrated in Figure 3, the post segment consists of a double flanged cylinder with a uniform wall thickness. The post assembly consists of three identical segments stacked and separated by metal spacers.

The loads employed by the analysis and during lab testing closely represent the structural loads transferred to the support post via the cold mass fixed center cradle.

The support post structure is designed to witbstand shipping and handling loads (2.0 G vertical, $1.5 \mathrm{G}$ axial, $1.0 \mathrm{G}$ lateral) during transportation of the $50 \mathrm{~mm}$ magnet as well as quench and dead weight load during operation. The axial and lateral loads as well as quench, result in bending of the post. The vertical loads result in tensile and compressive loads. The maximum bending load is due to a lateral load acting at the center of the cold mass while the maximum compressive load, duc to shipping and handling, is acting along the post centerline. Rounded values equal to $1.5 \mathrm{G}$ and $2.0 \mathrm{G}$ were used for both the analysis and in the lab as bending and compressive loads respectively. Figure 4 shows the lateral $F_{L}$ and vertical $F_{v}$ forces acting at the center of the cold mass. 

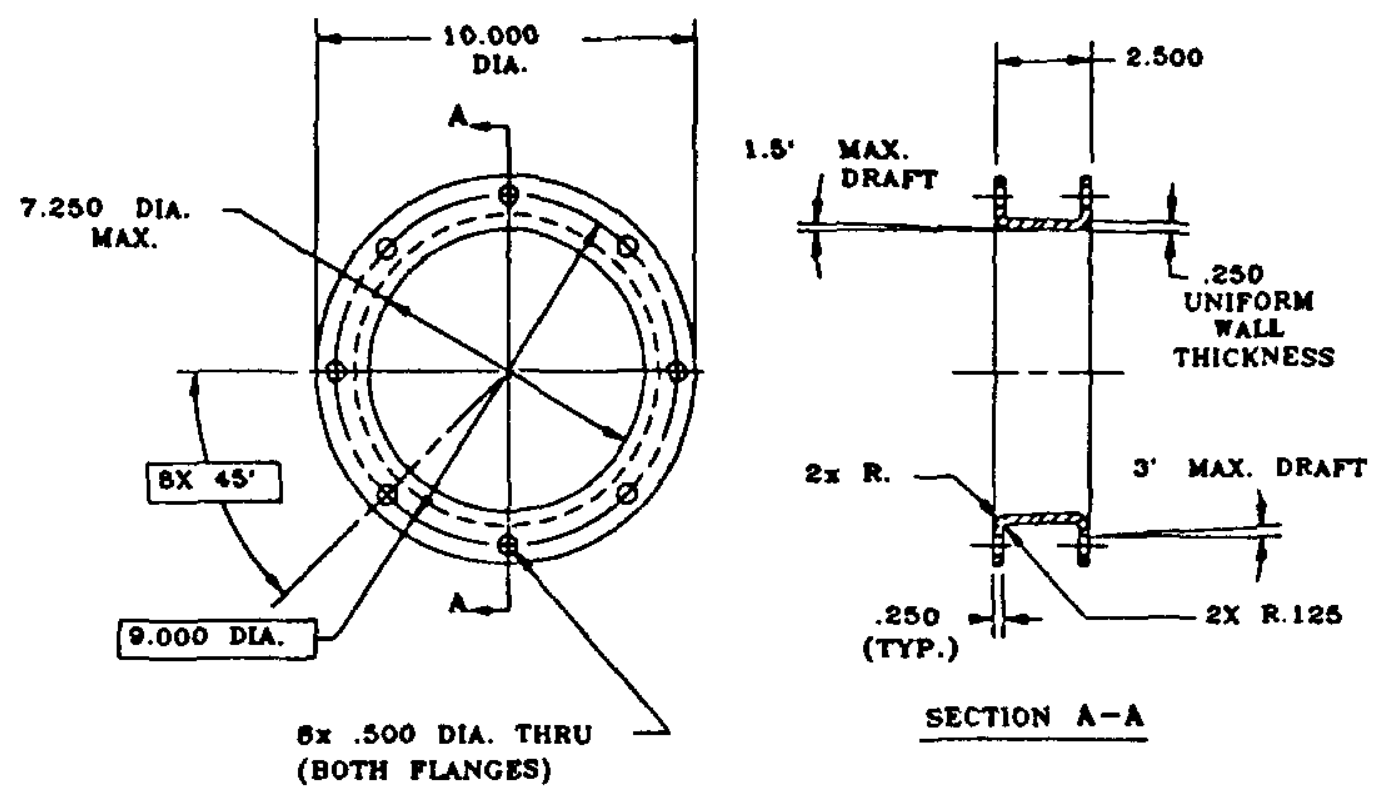

Figure 3. IMC Support Post Segment Cross Section

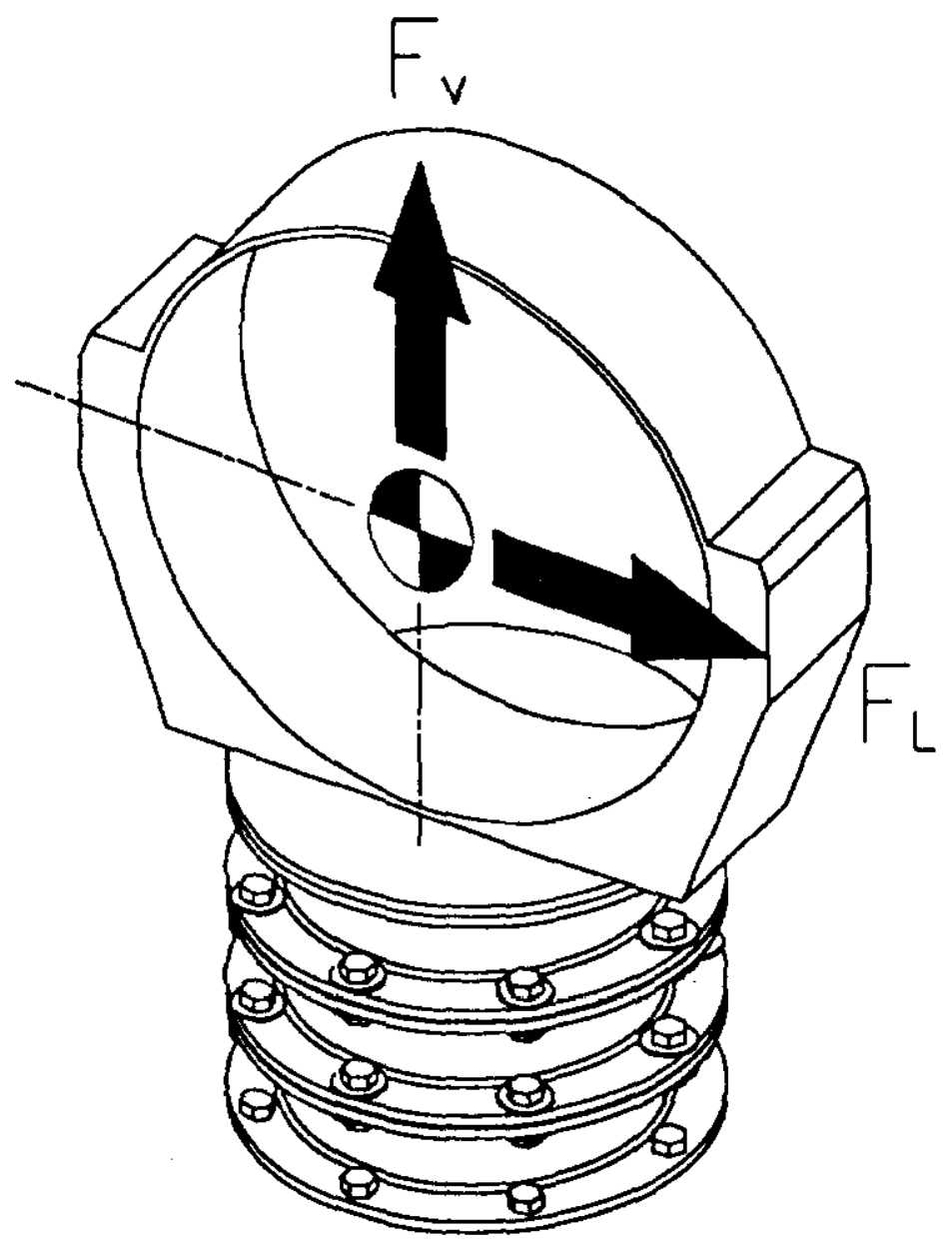

Figure 4. Load Direction and Notation 
An ANSYS program was employed to perform stress and deflection analysis of the IMC suppon post. For simplicity, only half of the post geometry is represented by the model while the other half is accounted for utilizing symmetry boundary conditions. The model is constructed using 3-D solid elements (Figure 5 ) and is constrained in all directions along its entire bottom surface. A 1.0 inch plate represents the stiffness of the cradle base plate and is constructed of 3-D quadrilateral shells. The loads are applied at a point 14.125 inches from the post bottom, which represents the cold mass centerline. A four beam frame consisting of 2-D beam elements is used to transmit the loads from the cold mass center to the 1.0 inch top plate. SY and UY denote vertical stress and displacement respectively while $S M_{X}$ denotes both lateral stress and displacement (Figure 6).

Values of flexural modulus were supplied as data by the vendors and were substituted for the modulus of elasticity commonly used for metals. The nexural strength was given and is defined as the maximum stress, in the surface fibers, in a beam in bending before it fails. This mechanical property is more commonly used in the study of composite materials.

As expected, the highest stresses resulted from bending due to lateral loading. As seen in Figure 7, the highest bending stress is concentrated in the web of the lower post section. It should be noted that the bolt holes in the flanges were not modelled thus, making it possible for slightly bigher stresses to exist. The maximum stresses due to tensile and compressive loading occurred in the outer web of the upper post section. The maximum bending stress is about 4.5 times greater than the maximum tensile and compressive stresses (see Table 4).

The maximum displacement in the $X$ direction $\left(S M_{x}\right)$, as a result of bending, occurs in the top flange of the upper post assembly. This upper section is also subjected to the highest magnitude of verical displacement. However, the maximum displacement due to bending is approximately six times greater than that due to tension and compression.

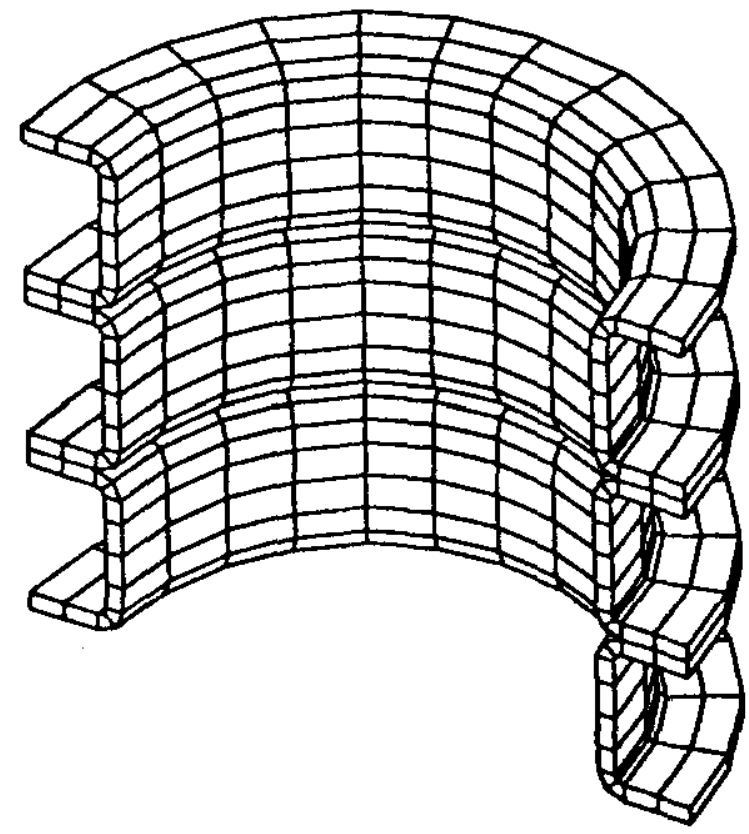

Figure 5. 3-D Solid Elements Model of IMC Post Assembly



Figure 6. Analysis Model -Load and Direction Notation 


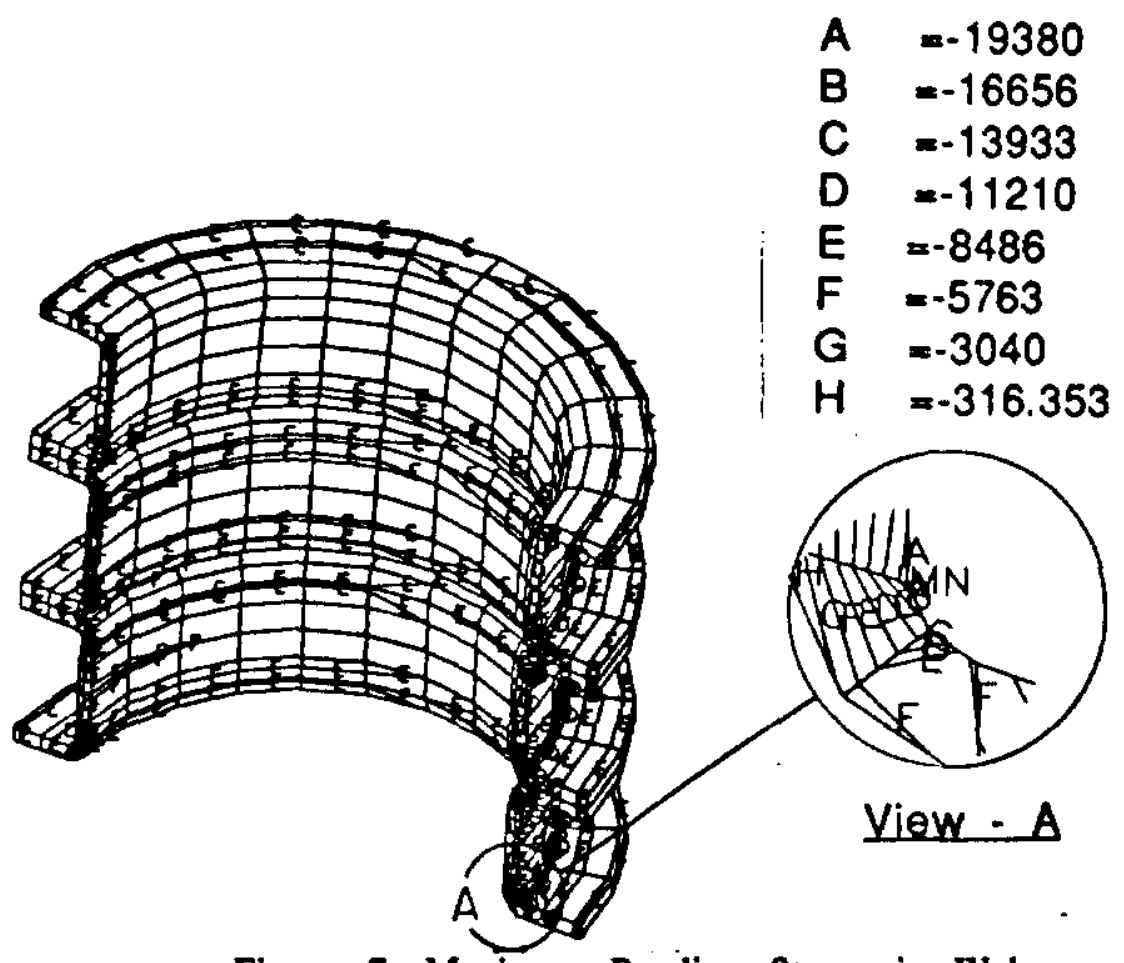

Figure 7. Maximum Bending Stress in Web For Ultem 2300 Assembly

\section{LABORATORY TEST}

The preliminary testing of the conceptual support post bas the following objectives:
a. Structual evaluation of the conceptual design
b. Evaluation of vendor's material information
c. Comparison of material's performance

In order to simulate the test with the post's actual loading conditions, the post bottom is fixed to the test stand while its top remains free. A 1.0 inch plate is mounted on top of the upper post section to simulate the cold mass cradle base. All loads were applied at the free end of the post. The tensile and compressive loads were applied along the post centerline. The bending force was applied 14.0 inches from the bottom at a plane perpendicular to the post centerline, to simulate the cold mass location. The loads were increased in increments of 1,000 pounds and limits were set at 10,000 pounds for teasion and compression and 7,400 pounds for bending. Each assembly was subjected to a maximum of five loading cycles.

The post testing stand is capable of applying tensile, compressive or bending load without the need to move the post assembly. The force is produced by adraulic actuation system. The applied force is measured by two independent methods for verification reasons. The first method incorporates $20,000 \mathrm{lb}$. load cell attached in line with the cylinder to measure force directly. The second method is comprised of pressure tranducers installed on each hydraulic line. The data acquisition system incorporates an acquisition/control unit connected to an IBM PC/XT through \& GPIB interface. Strain gages are mounted $180^{\circ}$ apant on each section of the post assembly as shown in Figure 8. Dial indicators mounted at various locations along the post measure the post deflection. 


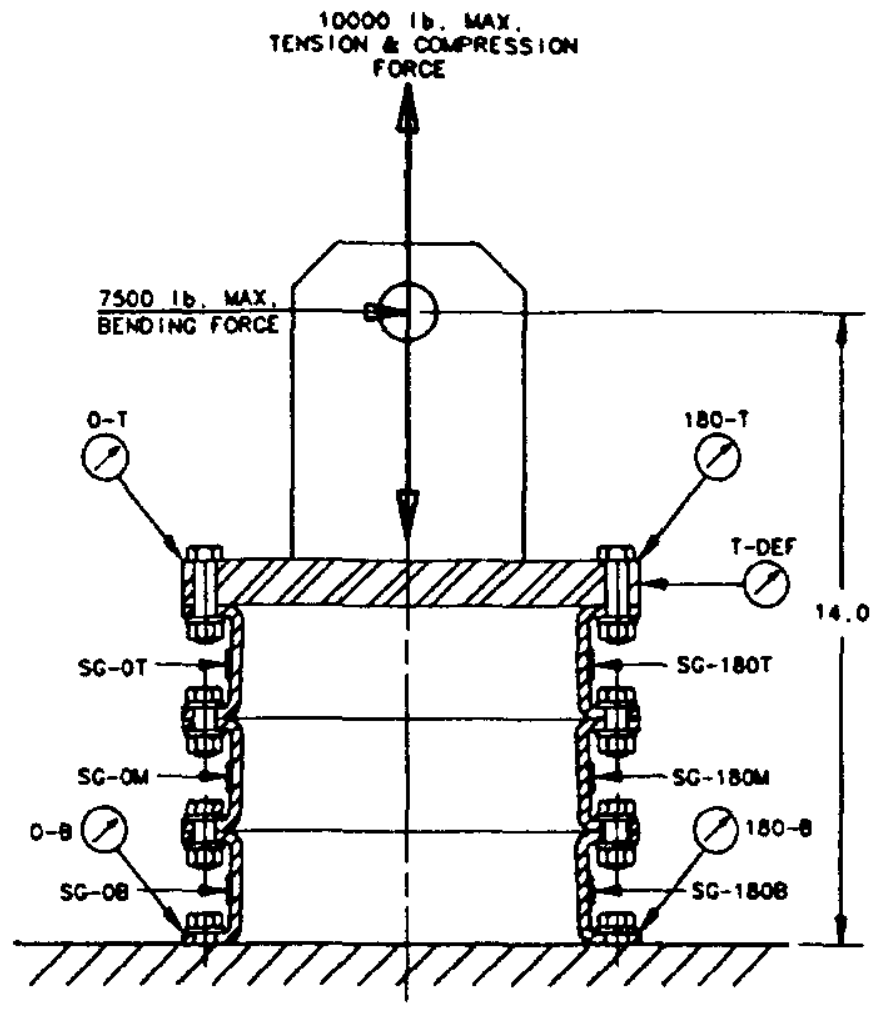

Figure 8. Lab Test Setup

Assuming a linear relation between stress and strain, stress values were derived by applying the following relationship.

$$
\mathbf{s}=\boldsymbol{e} \mathbf{E}
$$

where:

$$
\begin{aligned}
& \text { s - stress (psi) } \\
& \varepsilon \text { - strain }\left(\mu \varepsilon \times 10^{6}\right) \\
& \text { E - Modulus of elasticity (psi) }
\end{aligned}
$$

Three different IMC materials have been tested to date: G.E. Ultem 2300, Amoco Torlon 5030, and ICI PEEK 450GL30. The summary of test results are shown in Figure 9 through Figure 12 and Table 3.

Table 3. Summary of Lab Test Results

$\begin{array}{lccc}\text { Material } & \text { Ne. of Ass'y } & \text { Breaking Mede } & \text { Breaking Stress } \\ \text { Ultem 2300 } & 1 & \text { Bending } & 5,200 \mathrm{psi} \\ \text { Torion 5030 } & 2 & \text { Tension } & 4,500 \mathrm{psi} \\ \text { PEEK 450GL30 } & 1 & \text { Tension } & 3,500 \mathrm{psi}\end{array}$


As seen from Table 3, all post assemblies survived the compression test, yet only the Ultem 2300 made it through the tension and compression test to the bending lest. The assemblies made of Torlon 5030 and PEEK 450 GL30 failed during the tensile test.

TORLON - ULTEM - PEEK COMPRESSION TESTS

Compressive Strese vs. Force

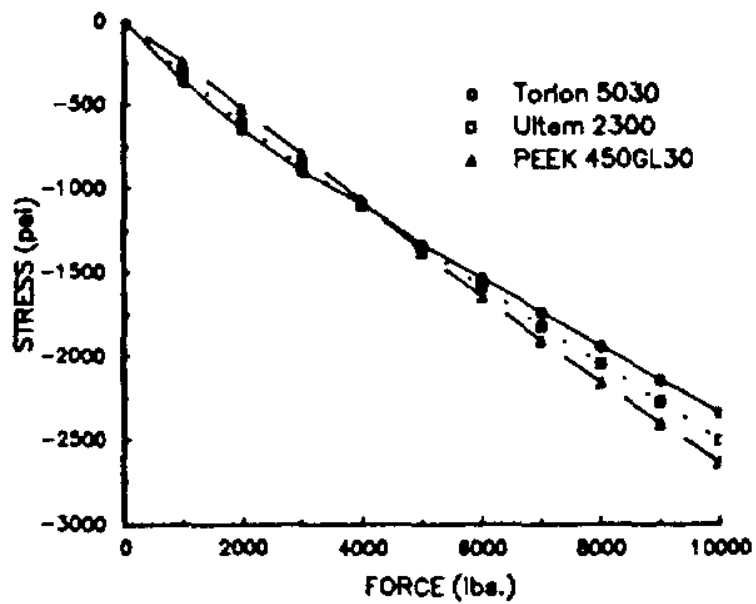

Figure 9
TORLON - ULTEM - PEEK COMPRESSION TESTS

Deflection ve Force

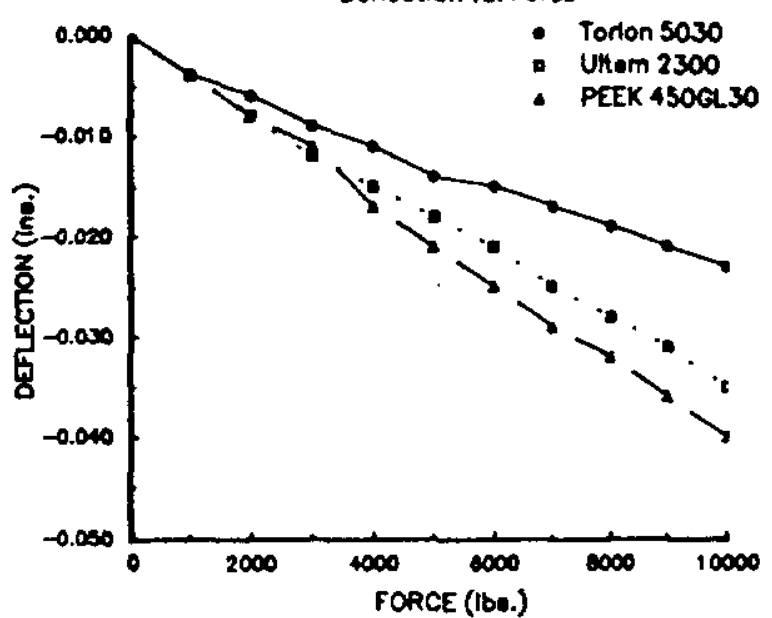

Figure 10

TORLON - ULTEM - PEEK TENSION TESTS

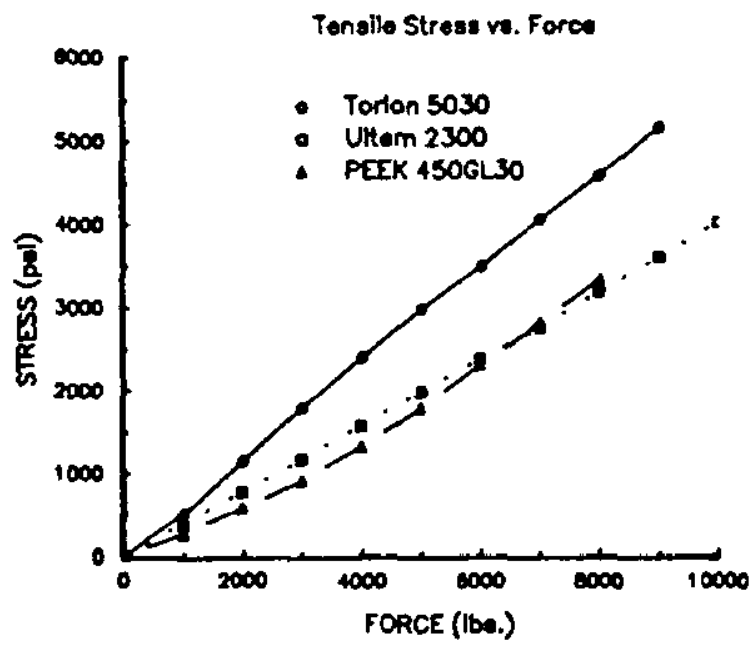

Figure 11
Doflection ve. Force

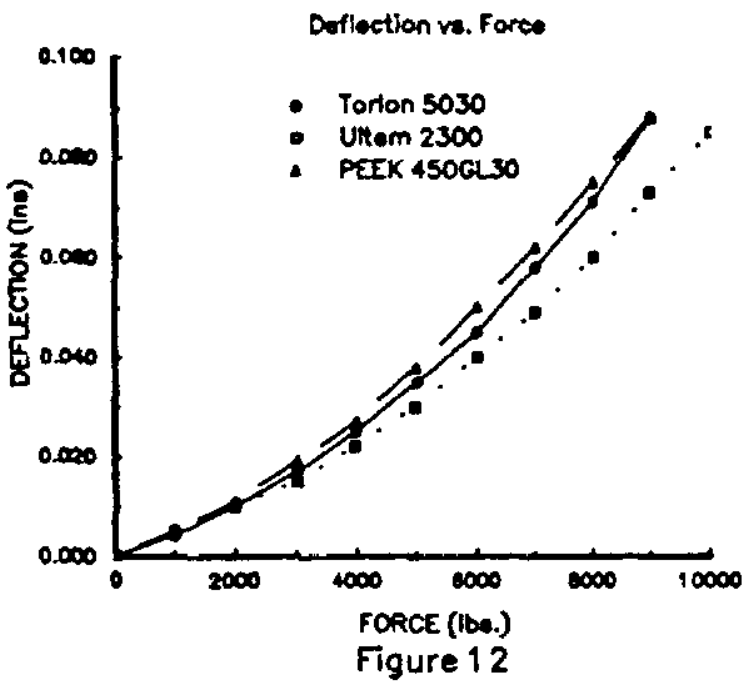




\section{DISCUSSION}

A total of three different materials were tested in the lab and analyzed. Judging by the values presented in the comparison Table 4, there is not a good correlation between the analysis and the test results.

Several factors may have contributed to this difference in results which are presently inconclusive:

- Parts did not perform up to vendors specifications due to inadequate processing procedure of the resin prior to molding.

- Unexpected high levels of stress concentrations due to material flow paths around corners, holes as well as machining marks.

- The stress analysis program used did not take into consideration holes and may not conform itself for analyzing injection molded composites (IMC).

The Torlon parts were machined out of compression molded bushing blanks. It is presumed that parts machined out of injection molded blanks will yield higher properties.

There is an agreement between the analysis and the lab results as to the high stress locations. In tension the analysis shows the high stress location to be in the web near the two flanges, adjacent to the corner radius. Indeed that is where both the Torlon and the PEEK sections failed. Both sheared along the web perimeter. The PEEK assembly also experienced failure along the section parting line in the web. In bending the analysis shows the high stress area to be in the web's low section along the plane of the acting force. Similarly this was found to be true in the lab as well when Ultem assembly failed during bending test at this location.

Preliminary stress calculations have indicated that a thicker web is required to withstand the loading conditions. The present configuration with constant wall thickness was adopted for preliminary testing to satisfy molding requirements.

Comparing analysis for lateral deflection at the top of both the reentrant and the IMC support posts shows the results to be within $10 \%$. However, the analyzed vertical displacement at the top of the reentrant post is about ten times lower. Presumably, this is caused by modeling assumptions that may not accurately reflect the actual assembly conditions. This is being investigated. Maximum bending stresses as well are within the same range, which is an indication to the correctness of the IMC post analysis. Preliminary heat leak calculations based on data for Ultem 2300 show a heat leak within the range of the requirements.

Table 4. Comparison of Analysis and Lab Results

\begin{tabular}{|c|c|c|c|c|c|c|c|c|}
\hline & & \multicolumn{3}{|c|}{ Uitem-2200 } & \multicolumn{2}{|c|}{ Torlon-5030 } & \multicolumn{2}{|c|}{ Pack 45CISO } \\
\hline Load Type & Locntion & Modo & Anelyale & Lab & Anslyais & Iab & Analyois & $\overrightarrow{t a b}$ \\
\hline $\begin{array}{l}\text { Tan aion } \\
10000 \mathrm{lb}\end{array}$ & $\begin{array}{l}180-\mathrm{T} \\
80-180 \mathrm{~T}\end{array}$ & $\begin{array}{l}\text { Dofiction (in) } \\
\text { 8troences (pen) }\end{array}$ & .002 & $\begin{array}{l}.033 \\
4000\end{array}$ & .015\%000 & 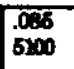 & \begin{tabular}{|l}
$.018^{\cdots \cdots 0}$ \\
$2814^{* 0}$
\end{tabular} & .000 \\
\hline $\begin{array}{l}\text { Compractiod } \\
10000 \mathrm{lb}\end{array}$ & $\begin{array}{l}180-T \\
\text { SO-180T }\end{array}$ & $\begin{array}{l}\text { Doflection (in) } \\
\text { stromed (pal) }\end{array}$ & .002 & $\begin{array}{l}.036 \\
.2500\end{array}$ & $\begin{array}{l}.017 \\
-000\end{array}$ & $\begin{array}{l}.028 \\
-2250\end{array}$ & $\begin{array}{l}-.020 \\
-20.87\end{array}$ & $\begin{array}{l}.040 \\
2700\end{array}$ \\
\hline $\begin{array}{l}\text { Bending } \\
3000 \mathrm{~b}\end{array}$ & $\begin{array}{l}\text { PT.DBF } \\
\text { Sa-180B }\end{array}$ & $\begin{array}{l}\text { Dedection (in) } \\
\text { Stroenes (ped) }\end{array}$ & .0400 & $\begin{array}{l}.140 \\
8000\end{array}$ & & & & \\
\hline
\end{tabular}




\section{CONCLUSION}

As it was reiterated throughout this paper, it was known previously that the post configuration presented here is only the preliminary design configuration. Having this simplified configuration helps reduce the number of unknowns such as materials, structural behavior of IMC under loads and the correlation between the lab test and the stress analysis. Although most of the objectives have been reached, more questions are yet to be answered. We have better understanding of the way different materials behave under load, yet some more materials like Dupont Vespel, Allied Signal CryoRad, Celazole and others need to be looked into. Other methods of producing the post section such as the insertion of a continuous fiber profile in the mold or use of Resin Transfer Molding (RTM) process have great potential of improving the strength and creep performance and need to be studied. Optimizing the shape and configuration of the post section in order to reduce the stress concentration would be a natural extension of the work done thus far and in fact is being analyzed presently. Future work will include the following items:

- Improving the material handling of Ultem during injection.

- Machining of Torlon post section parts out of injection molded bushings.

- Drilling of bolt holes as a secondary operation after injection molding.

- Increasing the corner radius between the web and the flanges.

It is expected that all the above actions will improve the present performance. Thermal analysis will follow at a later stage of the design.

Given the potential of substantially reducing the cost of the present support post (5 to 10 times) and simplifying its assembly process, it is strongly recommended to further investigate this concept of the IMC support post. More so, in light of the fact that the future Brookhaven RHIC accelerator will have a suspension system consisting of IMC support posts.

\section{ACKNOWLEDGEMENTS}

The authors gratefully acknowlege the sincere contribution and professional performance of the laboratory and drafting teams, as well as $P$. Whitson.

\section{REFERENCES}

1. Nicol, T.H., et al., "Design and Analysis of the SSC Dipole Magnet Suspension System," Proceedings of the 1989 International Industrial Symposium on the Super Collider (IISSC), New Orleans, Louisiana, February 8-10, 1989.

2. SSC Laboratory, "15 Meter Collider Dipole Magnet Prime Item Development Specification," MSD-F-001, March, 1990.

3. Sondericker, J.H. and L.J. Wolf, "Altemative Concepts for Structurally Supporting the Cold Mass of a Superconducting Accelerator Magnet," Proceedings of the 1991 International Industrial Symposium on the Super Collider (IISSC), Atlanta, Georgia, March, 13-15, 1991. 